\title{
Clinicopathological features and prognosis in patients with idiopathic membranous nephropathy with hypertension
}

\author{
WANJUN LU, SHUHAO GONG, JUAN LI and YING WANG
}

Department of Nephrology, The First Affiliated Hospital of Nanchang University, Nanchang, Jiangxi 330006, P.R. China

Received May 28, 2019; Accepted November 6, 2019

DOI: $10.3892 /$ etm.2020.8506

\begin{abstract}
The present study analyzed the clinicopathological features and prognosis in patients with idiopathic membranous nephropathy (IMN) with hypertension. In the hypertension group, significant differences were found in the age, hypertension history, systolic blood pressure, diastolic blood pressure (DBP), mean arterial pressure, albumin, serum creatinine, low-density lipoprotein, $24 \mathrm{~h}$ urine protein levels, calculated estimated glomerular filtration rate (e-GFR), glomerular sclerosis, segmental sclerosis, ischemic sclerosis, interstitial fibrosis, tubular atrophy and vascular lesion compared with the non-hypertension group $(\mathrm{P}<0.05)$. The average follow-up time was 35.70 months (5.10-103.77 months). In total, 54 patients reported a $50 \%$ decline in e-GFR, eight patients reported progression of disease to end-stage renal disease (ESRD) and nine cases of mortality were reported. Survival analysis results suggested that patients with hypertension had a lower cumulative renal survival rate than those without hypertension $(\mathrm{P}=0.034)$. Multivariate Cox hazards regression analysis results suggested that DBP [hazard ratio $(\mathrm{H}), 5.160$; CI, 0.865-0.989; $\mathrm{P}=0.023$ ], age (H, 4.839; CI, 1.008-1.142; $\mathrm{P}=0.028)$, sex $(\mathrm{H}, 5.680 ; \mathrm{CI}, 0.031-0.714 ; \mathrm{P}=0.017)$, serum creatinine $(\mathrm{H}, 20.920 ; \mathrm{CI}, 1.035-1.089 ; \mathrm{P}<0.001)$, uric acid $(\mathrm{H}, 4.783$; CI, 0.982-0.0.999; $\mathrm{P}=0.029), 24 \mathrm{~h}$ urine protein (H, 6.318; CI, 1.079-1.850; $\mathrm{P}=0.012)$, e-GFR (H, 4.008; CI, 1.001-1.062; $\mathrm{P}=0.045)$ and glomerular sclerosis $(\mathrm{H}, 8.722$; CI, 1.860-21.559; $\mathrm{P}=0.003)$, segmental sclerosis $(\mathrm{H}, 7.737$; CI, 7.770-13.219; $\mathrm{P}=0.005)$, percentage of ischemic sclerosis (H, 4.729; CI, 1.444-11.945; P=0.030), crescents (H, 5.938; CI, $0.003-0.526 ; \mathrm{P}=0.015)$, interstitial fibrosis and tubular atrophy (H, 8.128; CI, 0.005-1.052; $\mathrm{P}=0.043)$, and vascular lesion (H, 4.049; CI, 1.030-9.766; $\mathrm{P}=0.044)$ were risk factors for the development of IMN into ESRD. The results suggested that DBP may be an independent risk factor for the development of IMN with hypertension.
\end{abstract}

Correspondence to: Dr Ying Wang, Department of Nephrology, The First Affiliated Hospital of Nanchang University, 17 Yongwai Zheng, Nanchang, Jiangxi 330006, P.R. China

E-mail:wy1868@yeah.net

Key words: idiopathic membranous nephropathy, hypertension, characteristic, prognosis

\section{Introduction}

Idiopathic membranous nephropathy (IMN) is an organ-specific autoimmune inflammatory disease of the kidneys (1). IMN is the primary glomerular disease affecting adults $>60$ years of age and is a common cause of adult-onset nephropathy syndrome (NS) (1-3). IMN is characterized by thickening of the basement membrane (4) with subepithelial deposits of immune complexes mostly composed of immunoglobulin (Ig)G and the complement protein $\mathrm{C} 3(5,6)$, which are detectable using immunofluorescence or electron microscopy. Clinical presentations of IMN vary from subnephropathy range proteinuria to NS with heavy proteinuria, also including hypertension, renal insufficiency and microscopic hematuria (7). Previous studies of the natural history of IMN have reported that 5-30 and $40 \%$ of patients with IMN have spontaneous complete or partial remission after 5 years, respectively, whereas IMN in $30-40 \%$ of patients progresses to end-stage renal disease (ESRD) within 5-15 years $(8,9)$. Among hospitalized patients with primary glomerular nephropathy, a decreasing trend in IgA nephropathy and an increasing trend of IMN were reported by some researchers (10). Globally, hypertension acts as one of the leading etiologies for chronic kidney disease (CKD) (11). Moreover, as some patients have CKD due to high blood pressure, hypertension is considered secondary to renal diseases (12). A previous study reported that high blood pressure during renal biopsy is a poor prognostic factor of patients with IMN (13). The association between IMN and hypertension is not fully understood up to now. The present study hypothesized that hypertension worsens IMN prognosis and serves a central role in IMN disease progression. The present study investigated whether hypertension was associated with clinical parameters in IMN and examined IMN prognosis. Therefore, these clinicians can monitor and treat patients with PMN who may be inclined to hypertension, as to reduce occurrence of patients with PMN with hypertension and delay disease progression.

\section{Materials and methods}

Study population. The present retrospective study recruited patients with IMN from The First Affiliated Hospital of Nanchang University (Nanchang, China) between January 2010 and June 2018. NS was defined according to the standard criteria used in Japan (14): i) Urine protein excretion (3.5 g/day); ii) serum 
albumin $(3.0 \mathrm{~g} / \mathrm{dl})$ or serum total protein $(6.0 \mathrm{~g} / \mathrm{dl})$; iii) presence of edema; and iv) total cholesterol $(250 \mathrm{mg} / \mathrm{dl})$. The first and second criteria are considered necessary to diagnose IMN (15). According to the Kidney Disease Improving Global Outcomes (KDIGO) clinical practice guidelines for glomerulonephritis, IMN can be diagnosed by kidney biopsy (16). Patients with systemic diseases, such as rheumatic diseases, malignant tumors, hepatitis $\mathrm{B}$ or $\mathrm{C}$ virus infection, tuberculosis and other kidney diseases were excluded from the study (17-20). Patients $<18$ years old were also excluded. A total of 220 patients (male, 137; female, 83; age, 18-75 years; mean age 51.21 \pm 12.78 years) with previously diagnosed IMN were included in the study. The inclusion criteria were as follows: i) Age, 18-75 years; ii) MN diagnosed by renal biopsy; iii) informed consent form signed voluntarily by the participant; and iv) antihypertensive drugs were administered, but no statins or other drugs were received. The exclusion criteria were as follows: i) Patients with infections, malignant tumors, tuberculosis or other serious kidney diseases; ii) patients with insufficient follow-up; and iii) patients determined to be inappropriate for participation in the study by an investigator. The study was reviewed and approved by The Ethics Committee of The Nanchang University Hospital. All patients signed a patient consent form.

Study design. The enrolled patients were divided into two groups based on the criteria for hypertension: Hypertension and non-hypertension groups. Hypertension was defined as average systolic blood pressure (SBP) $\geq 140 \mathrm{mmHg}$ or average diastolic blood pressure (DBP) $\geq 90 \mathrm{mmHg}$ (21). Patients with a history of hypertension whose BP was not above the mentioned level following hospitalization with antihypertensive drugs were also classified under the hypertension group. BP was measured by an experienced physician using a mercury sphygmomanometer and an appropriately sized cuff applied to the right arm at heart level after $\geq 5$ min of rest in a seated position. The present study examined 100 patients with IMN and hypertension (hypertension group) and 120 patients with IMN without hypertension (non-hypertension group) who underwent renal biopsy at The First Affiliated Hospital of Nanchang University.

Clinical parameters. Basic demographic data included age, sex, course of the disease, edema, hypertension history, SBP, DBP and mean arterial pressure (MAP). The present study measured red blood cell count (RBC), hemoglobin ( $\mathrm{Hb})$, total protein (TP), albumin, serum creatinine (Scr), uric acid (UA), potassium $(\mathrm{K})$, calcium $(\mathrm{Ca})$, phosphorus $(\mathrm{P})$, triglycerides (TG), total cholesterol (TC), high-density lipoprotein (HDL), low-density lipoprotein (LDL) and calculated estimated glomerular filtration rate (e-GFR) were collected from 220 patients with IMN.The e-GFR was calculated using the CKD-EPI creatinine equation recommended by the KDIGO and was expressed as $\mathrm{ml} / \mathrm{min} / 1.73 \mathrm{~m}^{2}$ of body surface area (22). In addition, $24 \mathrm{~h}$ urine protein was measured.

Histopathologic parameters. The kidney biopsy specimens frozen as $5 \mu \mathrm{m}$ sections, dried at room temperature for $30 \mathrm{~min}$, fixed using acetone at $4^{\circ} \mathrm{C}$ for $10 \mathrm{~min}$ and washed three times using PBS. Fluorescein labeled antibody [Rabbit Anti Human IgG/FITC; cat. no. GF020229; 1:80; Rabbit Anti Human
IgA/FITC; cat. no. GF020429; 1:40; Rabbit Anti Human IgM/FITC cat. no. GF020329; 1:40; Rabbit Anti Human Fibrinogen/FITC; cat. no. GF011129; 1:40; Rabbit Anti Human C1q Complement/FITC; cat. no. GF025429; 1:40; Rabbit Anti Human C3c Complement/FITC; cat. no. GF020129; 1:20; all, Gene Tech (Shanghai) Co., Ltd.] was used and incubate with $37^{\circ} \mathrm{C}$ for $30 \mathrm{~min}$. Tissues were watched with PBS three times and sealed using glycerin. Tissues were then observed using fluorescence microscope (magnification, x100; eyepiece, magnification, x10; objective magnification, x10). Renal biopsy specimens including $\geq 10$ glomeruli were analyzed. All renal biopsies were processed according to the standard techniques of light microscopy (magnification, x400), immunofluorescence microscopy (magnification, $x 400$ ) and electron microscopy (magnification, x2,000) (7). To confirm the pathology, all samples were reviewed by two pathologists in The First Affiliated Hospital of Nanchang University. The following parameters were assessed by histopathology: Glomerular sclerosis, segmental sclerosis, ischemic sclerosis, crescents, mesangial cells and matrix hyperplasia. In addition, mesangial hypercellularity, interstitial fibrosis, tubular atrophy and vascular lesions were measured. These parameters was analyzed using SPSS software (version 22.0; IBM Corp.).

End-point of the study. Disease progression was defined as a $\geq 50 \%$ decline in the baseline e-GFR, doubling of Scr levels, diagnosis of ESRD and requiring renal replacement therapy after follow-up (23), including hemodialysis, peritoneal dialysis and kidney transplant, and death. The present study reviewed the medical record of each patient retrospectively from the date of renal biopsy to death, the development of ESRD or the last clinical visit (November 15, 2018). The average follow-up was 35.70 months.

Statistical analysis. Statistical analysis was performed using SPSS software (version 22.0; IBM Corp.). Continuous data are presented as the mean $\pm \mathrm{SD}$, whereas categorical data are presented as frequencies and percentages. Differences in continuous variables between the two groups were assessed using independent t-tests. A comparison of univariate predictors of clinical outcomes between the groups was performed using $\chi^{2}$ test for categorical variables. The renal progression-free rates were calculated using the Kaplan-Meier analysis and comparisons between the groups were performed using the log-rank test. Multivariate Cox proportional hazard regression analysis was performed to determine independent variables associated with the renal outcomes. The results are presented as hazard ratio $(\mathrm{H})$ with a $95 \% \mathrm{CI}$. $\mathrm{P}<0.05$ was considered to indicate a statistically significant difference.

\section{Results}

Comparison of demographic and laboratory parameters between the two groups. IMN is known to be a common cause of primary glomerulopathy (10). The present study examined 100 patients with IMN associated with hypertension (hypertension group) and 120 patients with IMN without hypertension (non-hypertension group) that underwent renal biopsy at The First Affiliated Hospital of Nanchang University. In the present study, the prevalence of hypertension was $45.45 \%$ among the 
Table I. Comparison of demographic and laboratory parameters between the two groups.

\begin{tabular}{|c|c|c|c|c|}
\hline Parameters & $\mathrm{HG}$ & NHG & T or $\chi^{2}$ & P-value \\
\hline Age, years & $54.34 \pm 13.10$ & $48.60 \pm 11.94$ & -3.4 & 0.001 \\
\hline Sex & & & 0.04 & 0.839 \\
\hline Male & $63(28.60)$ & $74(33.60)$ & & \\
\hline Female & $37(16.80)$ & $46(20.90)$ & & \\
\hline Course of disease & $5.81 \pm 8.55$ & $6.4 \pm 11.29$ & 0.43 & 0.668 \\
\hline Edema & & & 0.82 & 0.499 \\
\hline Yes & $92(41.80)$ & $106(48.20)$ & & \\
\hline No & $8(3.60)$ & $14(6.40)$ & & \\
\hline Hypertension history & & & 48.26 & $\mathrm{P}<0.001$ \\
\hline Yes & $34(15.50)$ & $0(0.00)$ & & \\
\hline No & $66(30.00)$ & $120(54.50)$ & & \\
\hline $\mathrm{SBP}, \mathrm{mmHg}$ & $144.07 \pm 19.28$ & $115.74 \pm 12.92$ & -12.54 & $\mathrm{P}<0.001$ \\
\hline DBP, mmHg & $90.66 \pm 13.08$ & $74.22 \pm 8.95$ & -10.66 & $\mathrm{P}<0.001$ \\
\hline MAP, $\mathrm{mmHg}$ & $108.46 \pm 13.31$ & $88.06 \pm 8.97$ & -13.05 & $\mathrm{P}<0.001$ \\
\hline $\mathrm{RBC} \times 10^{12} / 1$ & $4.35 \pm 0.67$ & $4.38 \pm 0.71$ & 0.31 & 0.758 \\
\hline $\mathrm{Hb}, \mathrm{g} / \mathrm{l}$ & $129.19 \pm 22.21$ & $128.35 \pm 19.35$ & -0.3 & 0.765 \\
\hline $\mathrm{TP}, \mathrm{g} / \mathrm{l}$ & $46.96 \pm 8.48$ & $47.35 \pm 8.02$ & 0.35 & 0.727 \\
\hline Alb, g/l & $23.50 \pm 6.75$ & $25.20 \pm 6.01$ & 2.01 & 0.046 \\
\hline Scr, g/l & $91.1 \pm 46.68$ & $74.25 \pm 24.93$ & -3.25 & 0.001 \\
\hline $\mathrm{UA}, \mu \mathrm{mol} / \mathrm{l}$ & $371.56 \pm 78.67$ & $367.34 \pm 93.28$ & -0.36 & 0.72 \\
\hline $\mathrm{K}, \mathrm{mmol} / \mathrm{l}$ & $4.00 \pm 0.54$ & $4.01 \pm 0.45$ & 0.23 & 0.818 \\
\hline $\mathrm{Ca}, \mathrm{mmol} / \mathrm{l}$ & $2.02 \pm 0.18$ & $2.06 \pm 0.16$ & 1.63 & 0.104 \\
\hline $\mathrm{P}, \mathrm{mmol} / \mathrm{l}$ & $1.18 \pm 0.19$ & $1.14 \pm 0.22$ & -1.13 & 0.26 \\
\hline $\mathrm{TG}, \mathrm{mmol} / \mathrm{l}$ & $3.15 \pm 2.55$ & $2.57 \pm 2.11$ & -1.85 & 0.065 \\
\hline $\mathrm{TC}, \mathrm{mmol} / \mathrm{l}$ & $7.25 \pm 2.01$ & $6.78 \pm 1.91$ & -1.79 & 0.075 \\
\hline HDL, mmol/1 & $1.48 \pm 0.59$ & $1.59 \pm 0.68$ & 1.3 & 0.196 \\
\hline $\mathrm{LDL}, \mathrm{mmol} / \mathrm{l}$ & $5.03 \pm 2.14$ & $4.40 \pm 1.73$ & -2.38 & 0.018 \\
\hline 24 h UP g/24 h & $4.56 \pm 2.52$ & $3.83 \pm 2.35$ & -2.21 & 0.028 \\
\hline e-GFR & $81.83 \pm 35.32$ & $94.09 \pm 36.65$ & 2.51 & 0.013 \\
\hline
\end{tabular}

$\mathrm{n}=220$. Data are presented as mean \pm SD or percentages (in brackets). HG, hypertension group; NHG, non-hypertension group; SBP, systolic blood pressure; DBP, diastolic blood pressure; MAP, mean arterial pressure; RBC, red blood cell count; Hb, hemoglobin; TP, total protein; Alb, albumin; Scr, serum creatinine; UA, uric acid; K, potassium; Ca, calcium; P, phosphate; TG, triglyceride; TC, total cholesterol; HDL, high density lipoprotein; LDL, low-density lipoprotein; $24 \mathrm{~h} \mathrm{UP,} 24 \mathrm{~h}$ urine protein; e-GFR, calculated estimated glomerular filtration rate.

patients. Baseline characteristics of patients with and without hypertension are summarized in Table I. Among the patients, $137(62.2 \%)$ were male and $83(37.7 \%)$ were female, with a male to female ratio of $1.65: 1$. The mean age of patients with IMN was $51.21 \pm 12.78$ years. A significant difference was found in the age $(\mathrm{P}=0.001)$, hypertension history $(\mathrm{P}<0.0001)$, SBP $(\mathrm{P}<0.0001)$, DBP $(\mathrm{P}<0.0001)$, MAP $(\mathrm{P}<0.0001)$, albumin $(\mathrm{P}=0.046), \mathrm{Scr}(\mathrm{P}=0.001), \mathrm{LDL}(\mathrm{P}=0.018), 24 \mathrm{~h}$ urine protein $(\mathrm{P}=0.028)$ and $\mathrm{e}-\mathrm{GFR}(\mathrm{P}=0.013)$ between the groups with and without hypertension. There were no significant differences in the following parameters between the two groups: Sex, course of the disease, edema, RBC, Hb, TP, UA, K, Ca, P, TG, TC and HDL.

Comparison of pathological parameters between the two groups. Analysis of pathological parameters between the hypertension and non-hypertension groups is shown in Table II. Ischemic sclerosis and vascular lesions were associated with hypertension in IMN. The present univariate analysis results suggested that glomerular sclerosis, segmental sclerosis, ischemic sclerosis, interstitial fibrosis, tubular atrophy and vascular lesions were associated with the primary outcome in patients with IMN and hypertension.

Survival analysis of cumulative renal survival rate of hypertension and non-hypertension groups, and riskfactors associated with patients with IMN and hypertension developing into ESRD. Follow-up data were available for 220 patients with IMN with and without hypertension. Average observation time was 35.70 months (range, 5.10-103.77 months). In total, 54 patients reported a $50 \%$ decline in e-GFR or doubling of Scr levels. During follow-up, in eight patients IMN had progressed 
Table II. Comparison of pathological parameters between the two groups.

\begin{tabular}{|c|c|c|c|c|}
\hline Parameter & $\mathrm{HG}$ & NHG & $\mathrm{T}$ or $\chi^{2}$ & P-value \\
\hline GS, case $(\%)$ & $31(14.09)$ & $33(15.00)$ & 0.778 & 0.036 \\
\hline PGS (\%) & $0.06 \pm 0.11$ & $0.04 \pm 0.09$ & -1.32 & 0.188 \\
\hline $\mathrm{SS}$, case $(\%)$ & $3(1.36)$ & $4(1.82)$ & -0.15 & 0.048 \\
\hline PSS (\%) & $0.004 \pm 0.02$ & $0.004 \pm 0.02$ & -0.08 & 0.939 \\
\hline IS, case (\%) & $27(12.27)$ & $28(12.73)$ & -0.822 & 0.011 \\
\hline PIS (\%) & $0.04 \pm 0.10$ & $0.05 \pm 0.13$ & 0.14 & 0.886 \\
\hline Crescent, case (\%) & $8(3.64)$ & $7(3.18)$ & -0.65 & 0.515 \\
\hline Percentage of crescents (\%) & $0.02 \pm 0.08$ & $0.004 \pm 0.02$ & -1.56 & 0.122 \\
\hline MC/MAH & & & 2.351 & 0.314 \\
\hline 0 & $15(6.82)$ & $19(8.64)$ & & \\
\hline$<25 \%$ & $60(27.27)$ & $81(36.82)$ & & \\
\hline $25-49 \%$ & $25(11.36)$ & $20(9.09)$ & & \\
\hline $50-74 \%$ & $0(0.00)$ & $0(0.00)$ & & \\
\hline$>75 \%$ & $0(0.00)$ & $0(0.00)$ & & \\
\hline $\mathrm{MEH}$ & & & 5.915 & 0.2 \\
\hline 0 & $15(6.82)$ & $23(10.45)$ & & \\
\hline$<25 \%$ & $23(10.45)$ & $24(10.91)$ & & \\
\hline $25-49 \%$ & $52(23.64)$ & $69(31.36)$ & & \\
\hline $50-74 \%$ & $8(3.64)$ & $2(0.91)$ & & \\
\hline$>75 \%$ & $2(0.91)$ & $2(0.91)$ & & \\
\hline IF & & & 5.399 & 0.038 \\
\hline 0 & $61(27.73)$ & $76(34.55)$ & & \\
\hline$<25 \%$ & $7(3.18)$ & $6(2.73)$ & & \\
\hline $25-49 \%$ & $26(11.82)$ & $36(16.36)$ & & \\
\hline $50-74 \%$ & $4(1.82)$ & $0(0.00)$ & & \\
\hline$>75 \%$ & $2(0.91)$ & $2(0.91)$ & & \\
\hline TA & & & 9.449 & 0.041 \\
\hline 0 & $18(8.18)$ & $25(11.36)$ & & \\
\hline$<25 \%$ & $20(9.09)$ & $29(13.18)$ & & \\
\hline $25-49 \%$ & $53(24.09)$ & $64(29.09)$ & & \\
\hline $50-74 \%$ & $7(3.18)$ & $0(0.00)$ & & \\
\hline$>75 \%$ & $2(0.91)$ & $2(0.91)$ & & \\
\hline $\mathrm{VL}$ & & & 1.107 & 0.023 \\
\hline Yes & $74(33.64)$ & $81(36.82)$ & & \\
\hline No & $26(11.82)$ & $39(17.73)$ & & \\
\hline
\end{tabular}

$\mathrm{n}=220$. Data are presented as mean \pm SD or percentages (in brackets). HG, hypertension group; NHG, non-hypertension group; GS, glomerular sclerosis; PGS, percentage of GS; SS, segmental sclerosis; PSS, percentage of SS; IS, is chemic sclerosis; PIS, percentage of IS; MC/MAH, mesangial cell and matrix hyperplasia; MEH, mesangial hypercellularity; IF, interstitial fibrosis; TA, tubular atrophy; VL, vascular lesion.

to ESRD. There were nine cases of mortality and the cause of death was unknown. The renal survival rates in patients with hypertension were significantly reduced compared with patients without hypertension (log-rank test, $\mathrm{P}=0.034$; Fig. 1). The present Cox proportional hazard regression results suggested that DBP may be an independent risk factor for IMN progression ( $\mathrm{H}, 5.160 ; \mathrm{CI}, 0.865-0.989 ; \mathrm{P}=0.023)$. The present results suggested that age $(\mathrm{H}, 4.839 ; \mathrm{CI}, 1.008-1.142 ; \mathrm{P}=0.028)$, sex (H, 5.680; CI, 0.031-0.714; P=0.017), Scr (H, 20.920; CI, 1.035-1.089; $\mathrm{P}<0.001)$, UA (H, 4.783; CI, 0.982-0.0.999; $\mathrm{P}=0.029), 24 \mathrm{~h}$ urine protein $(\mathrm{H}, 6.318 ; \mathrm{CI}, 1.079-0.1 .850$; $\mathrm{P}=0.012)$ and $\mathrm{e}-\mathrm{GFR}(\mathrm{H}, 4.008 ; \mathrm{CI}, 1.001-1.062 ; \mathrm{P}=0.045)$ were significant and independent risk factors in patients with IMN with hypertension. Glomerular sclerosis (H, 8.722; CI,
1.860-21.559; $\mathrm{P}=0.003)$, segmental sclerosis $(\mathrm{H}, 7.737$; $\mathrm{CI}$, 7.770-13.219; $\mathrm{P}=0.005)$, percentage of ischemic sclerosis (H, 4.729; CI, 1.444-11.945; $\mathrm{P}=0.030)$, crescents $(\mathrm{H}, 5.938$; CI, 0.003-0.526; $\mathrm{P}=0.015)$, interstitial fibrosis $(\mathrm{H}, 8.128$; CI, 0.005-1.052; $\mathrm{P}=0.043)$, and vascular lesions (H, 4.049; CI, 1.030-9.766; $\mathrm{P}=0.044)$ were also identified as significant and independent risk factors in patients with IMN with hypertension (Table III).

\section{Discussion}

IMN is the most common primary glomerular disease in individuals $>60$ years old (24). In patients with IMN, one-third of patients with spontaneous remission report progressive 
Table III. Multivariate Cox hazard regression analysis of the disease risk factors and patients with idiopathic membranous nephropathy with hypertension developing into end-stage renal disease.

\begin{tabular}{lcrrrrrr}
\hline & & & & & & & \multicolumn{2}{c}{$95.0 \%$ CI } \\
\cline { 5 - 8 } Parameter & B & SE & HR & P-value & Exp (B) & Lower & Upper \\
\hline Age, years & 0.070 & 0.032 & 4.839 & 0.028 & 1.073 & 1.008 & 1.142 \\
Sex & -1.899 & 0.797 & 5.680 & 0.017 & 0.150 & 0.031 & 0.714 \\
DBP, mmHg & -0.078 & 0.034 & 5.160 & 0.023 & 0.925 & 0.865 & 0.989 \\
Scr, $\mu$ mol/l & 0.060 & 0.013 & 20.920 & $<0.001$ & 1.062 & 1.035 & 1.089 \\
UA, $\mu$ mol/l & -0.010 & 0.004 & 4.783 & 0.029 & 0.990 & 0.982 & 0.999 \\
24 h urine protein, g & 0.346 & 0.138 & 6.318 & 0.012 & 1.413 & 1.079 & 1.850 \\
e-GFR & 0.030 & 0.015 & 4.008 & 0.045 & 1.031 & 1.001 & 1.062 \\
Glomerular sclerosis & 1.846 & 0.625 & 8.722 & 0.003 & 6.333 & 1.860 & 21.559 \\
Segmental sclerosis & 6.942 & 2.496 & 7.737 & 0.005 & 1034.718 & 7.770 & 13.219 \\
Percentage of IS & 3.722 & 1.711 & 4.729 & 0.030 & 41.328 & 1.444 & 11.945 \\
Crescents & -3.286 & 1.348 & 5.938 & 0.015 & 0.037 & 0.003 & 0.526 \\
Interstitial fibrosis & 0.010 & 0.013 & 8.128 & 0.043 & 1.023 & 0.005 & 1.052 \\
Vascular lesion & 1.154 & 0.574 & 4.049 & 0.044 & 3.172 & 1.030 & 9.766 \\
\hline
\end{tabular}

DBP, diastolic blood pressure; Scr, serum creatinine; UA, uric acid; e-GFR, calculated estimated glomerular filtration rate; IS ischemic sclerosis; B, regression coefficient; SE, standard error.

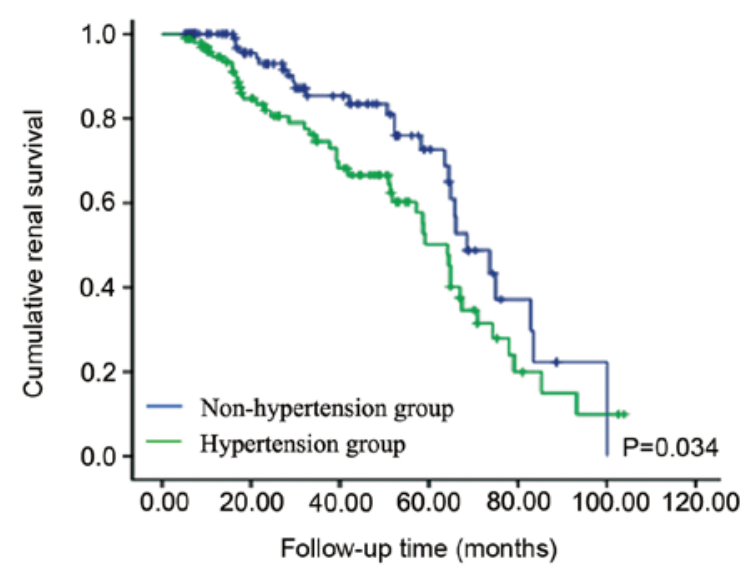

Figure 1. Survival analysis of the cumulative renal survival rate of the hypertension group and the non-hypertension group.

renal failure, whereas the remaining patients report stable renal function (25). Nephritic syndrome, massive proteinuria, hematuria, impaired renal function and hypertension are common in IMN (26). The results from previous studies on IMN prognostic factors are highly variable (12). In addition, whether demographic parameters, laboratory parameters and histological lesions contribute to the improvement of renal function in patients with hypertension is not fully understood.

The present retrospective study investigated the prognosis and risk factors for renal survival in patients with IMN with hypertension. In the present study, the majority of patients with IMN were $>40$ years. A higher incidence of hypertension among elderly patients compared with adult patients has previously been reported (27). The present results are consistent with the results of the previous studies $(28,29)$. Moreover, the present study identified that Scr, LDL and $24 \mathrm{~h}$ urine protein were increased, and serum albumin and e-GFR were decreased in patients with IMN with hypertension. Huh et al (18) reported that low serum albumin levels at the onset of the disease were associated with poor renal prognosis of patients with IMN. Another previous study reported that high levels of Scr at diagnosis are major predictors of the progression of IMN to ESRD (30). Proteinuria has also been used as a major predictor for renal prognosis of IMN in a conventional predictive model (31). Patients with limited proteinuria are deemed to have a better prognosis (31). Previous studies identified lower e-GFR to be significantly associated with the risk of progression of IMN to ESRD $(32,33)$. The present results suggested that hypertension may be associated with the severity of IMN, which is consistent with results from previous studies. In the majority of studies, hypertension was not indicated to be an independent predictor of MN $(34,35)$. To the best of our knowledge, the present study was the first to identify primary factors for hypertension development in patients with IMN using a retrospective study design, measuring parameters such as uric acid, age and sex (36).

The mechanism of hypertension and disease severity, and whether hypertension can exacerbate kidney disease is not fully understood. The present results suggested that age and sex were statistically significant between the hypertension and non-hypertension groups, which were in line with findings from a previous study (37). Uric acid was previously reported to be independently associated with prevalent CKD and hypertension $(36,38)$. Hypertension can cause nephroangiosclerosis (39). The severity of renal histological lesions, particularly of interstitial fibrosis, glomerular sclerosis and vasculopathy, are considered negative prognostic indicators for IMN (40). The present results suggested that interstitial fibrosis, glomerular sclerosis, vasculopathy and crescents were significantly different between the hypertension and non-hypertension 
groups. However, other parameters were not statistically significant in the present study, which may be attributed to the small sample size. The present results suggested that the accumulated survival rate was significantly higher in patients with IMN without hypertension compared with patients with hypertension. In the present study, a multivariate Cox proportional hazards regression analysis was performed to investigate the association of DBP with renal outcomes. A previous study showed that patients with IMN suffered from CKD as a result of hypertension, and that hypertension was secondary to renal disease (18). Therefore, monitoring BP during diagnosis in patients with IMN may facilitate prognosis.

The present study had several limitations, such as a small number of patients with IMN, which limited the statistical power of the study. Therefore, future studies with larger sample sizes and longer periods of follow-up are required to investigate the influence of BP in patients with IMN. In addition, the present study did not analyze antibodies against phospholipase A2 receptors and thrombospondin type I domain-containing 7A, which have been suggested to be correlated with IMN disease severity (41). Finally, the primary outcome of MN can be complete and partial remission, including remission of proteinuria (42); however, in the present study, quantitative proteinuria was not followed up at the end-point of the study.

In conclusion, the present results suggested that patients with IMN with hypertension reported worse clinicopathological features and lower cumulative renal survival rate compared with patients without hypertension. The present results suggested that DBP may be an independent risk factor for the development of IMN with hypertension. Early detection and correction of hypertension could help delay the deterioration of renal function and improve prognosis of patients with IMN.

\section{Acknowledgements}

Not applicable.

\section{Funding}

No funding was received.

\section{Availability of data and materials}

The datasets used and/or analyzed during the current study are available from the corresponding author on reasonable request.

\section{Authors' contributions}

WL wrote the manuscript. WL, SG and JL collected and analyzed the study data. SG performed the histological examination of the kidney. YW conceived and designed the study, proofread the manuscript and revised the manuscript for impoartant intellectual content. All authors read and approved the final manuscript.

\section{Ethics approval and consent to participate}

The present study was approved by The Ethics Committee of The First Affiliated Hospital of Nanchang University. Patients who participated in this research had complete clinical data. Signed informed consents were obtained from the patients or guardians (when the patient was incapacitated).

\section{Patient consent for publication}

Not applicable.

\section{Competing interests}

The authors declare that they have no competing interests.

\section{References}

1. Beck LH Jr and Salant DJ: Membranous nephropathy: From models to man. J Clin Invest 124: 2307-2314, 2014.

2. Sekula P,Li Y, Stanescu HC, Wuttke M,Ekici AB, Bockenhauer D, Walz G, Powis SH, Kielstein JT, Brenchley P, et al: Genetic risk variants for membranous nephropathy: Extension of and association with other chronic kidney disease aetiologies. Nephrol Dial Transplant 32: 325-332, 2017.

3. Pozdzik A, Brochériou I, David C, Touzani F, Goujon JM and Wissing KM: Membranous nephropathy and anti-podocytes antibodies: Implications for the diagnostic workup and disease management. Biomed Res Int 2018: 6281054, 2018.

4. Ronco P and Debiec H: Pathogenesis of membranous nephropathy: Recent advances and future challenges. Nat Rev Nephrol 8: 203-213, 2012

5. Sinico RA, Mezzina N, Trezzi B, Ghiggeri GM and Radice A: Immunology of membranous nephropathy: From animal models to humans. Clin Exp Immunol 183: 157-165, 2016.

6. Larsen CP, Messias NC, Silva FG, Messias E and Walker PD: Determination of primary versus secondary membranous glomerulopathy utilizing phospholipase A2 receptor staining in renal biopsies. Mod Pathol 26: 709-715, 2013.

7. Zhang XD, Cui Z, Zhang MF, Wang J, Zhang YM, Qu Z, Wang X, Huang J, Wang F, Meng LQ, et al: Clinical implications of pathological features of primary membranous nephropathy. BMC Nephrol 19: 215, 2018.

8. Beck Lh Jr, Bonegio RG, Lambeau G, Beck DM, Powell DW, Cummins TD, Klein JB and Salant DJ: M-type phospholipase A2 receptor as target antigen in idiopathic membranous nephropathy. N Engl J Med 361: 11-21, 2009.

9. van den Brand JA, Hofstra JM and Wetzels JF: Low-molecular-weight proteins as prognostic markers in idiopathic membranous nephropathy. Clin J Am Soc Nephrol 6: 2846-2853, 2011.

10. Xu X, Wang G, Chen N, Lu T, Nie S, Xu G, Zhang P, Luo Y, Wang Y, Wang X, et al: Long-term exposure to air pollution and increased risk of membranous nephropathy in China. J Am Soc Nephrol 27: 3739-3746, 2016.

11. Chiu HF, Chen H, Lu KC and Shu KH; Taiwan Society of Nephrology: Distribution of glomerular diseases in Taiwan: Preliminary report of national renal biopsy registry-publication on behalf of Taiwan society of nephrology. BMC Nephrol 19: 6, 2018.

12. da Silva AQB, de Sandes-Freitas TV, Mansur JB, MedicinaPestana JO and Mastroianni-Kirsztajn G: Clinical presentation, outcomes, and treatment of membranous nephropathy after transplantation. Int J Nephrol 2018: 3720591, 2018.

13. Tu WH, Petitti DB, Biava CG, Tulunay O and Hopper J Jr: Membranous nephropathy: Predictors of terminal renal failure. Nephron 36: 118-124, 1984.

14. Saito T, Iwano M, Matsumoto K, Mitarai T, Yokoyama H, Yorioka N, Nishi S, Yoshimura A, Sato H, Ogahara S, et al: Mizoribine therapy combined with steroids and mizoribine blood concentration monitoring for idiopathic membranous nephropathy with steroid-resistant nephrotic syndrome. Clin Exp Nephrol 21: 961-970, 2017.

15. Kida H, Asamoto T, Yokoyama H, Tomosugi $\mathrm{N}$ and Hattori $\mathrm{N}$ : Long-term prognosis of membranous nephropathy. Clin Nephrol 25: 64-69, 1986.

16. Tang Z, Wang Y, Tao L, Guo Y, Zheng Y and Zheng D: The elevated levels of urinary angiotensinogen are correlated with the severity of idiopathic membranous nephropathy. BMC Nephrol 19: 357, 2018. 
17. Di J, Qian Q, Yang M, Jiang Y, Zhou H, Li M and Zou Y: Efficacy and safety of long-course tacrolimus treatment for idiopathic membranous nephropathy. Exp Ther Med 16: 979-984, 2018.

18. Huh H, Lee H, Lee JP, Kim DK, Oh S, Oh YK, Kim YS and Lim CS: Factors affecting the long-term outcomes of idiopathic membranous nephropathy. BMC Nephrol 18: 104, 2017.

19. Liu YH, Chen CH, Chen SY, Lin YJ, Liao WL, Tsai CH, Wan L and Tsai FJ: Association of phospholipase A2 receptor 1 polymorphisms with idiopathic membranous nephropathy in Chinese patients in Taiwan. J Biomed Sci 17: 81, 2010.

20. Xu NX, Xie QH, Sun ZX, Wang J, Li Y, Wang L, Liu SJ, Xue J and Hao CM: Renal phospholipase A2 receptor and the clinical features of idiopathic membranous nephropathy. Chin Med J (Engl) 130: 892-898, 2017.

21. 1999 World Health Organization-International society of hypertension guidelines for the management of hypertension. Guidelines subcommittee. J Hypertens 17: 151-183, 1999.

22. Cattran DC, Feehally J and Terence Cook H: Kidney Disease: Improving Global Outcomes (KDIGO) CKD Work Group: KDIGO2012 clinical practice guideline for the evaluation and management of chronic kidney disease. Kidney Int (Suppl 3) S1-S150, 2013.

23. Nair V, Robinson-Cohen C, Smith MR, Bellovich KA, Bhat ZY, Bobadilla M, Brosius F, de Boer IH, Essioux L, Formentini I, et al: Growth differentiation factor-15 and risk of CKD progression. J Am Soc Nephrol 28: 2233-2240, 2017.

24. Cattran DC and Brenchley PE: Membranous nephropathy: Integrating basic science into improved clinical management Kidney Int 91: 566-574, 2017

25. Zhang Q, Huang B, Liu X, Liu B, Zhang Y, Zhang Z, Hua J, Fan Y, Hu L, Meng M, et al: Ultrasensitive quantitation of anti-phospholipase A2 receptor antibody as a diagnostic and prognostic indicator of idiopathic membranous nephropathy. Sci Rep 7: 12049, 2017.

26. Roy S, Korula A, Basu G, Jacob S, Varughese S and Tamilarasi V: Immunohistochemical glomerular expression of phospholipase A2 receptor in primary and secondary membranous nephropathy: A retrospective study in an Indian cohort with clinicopathological correlations. Nephron Extra 7: 1-9, 2017.

27. Calvo-Río V, Loricera J, Mata C, Martín L, Ortiz-Sanjuán F, Alvarez L, González-Vela MC, González-Lamuño D, Rueda-Gotor J, Fernández-Llaca $\mathrm{H}$, et al: Henoch-Schönlein purpura in northern Spain: Clinical spectrum of the disease in 417 patients from a single center. Medicine (Baltimore) 93 206-113, 2014.

28. Ayalon R and Beck LH Jr: Membranous nephropathy: Not just a disease for adults. Pediatr Nephrol 30: 31-39, 2015.

29. Couser WG: Primary membranous nephropathy. Clin J Am Soc Nephrol 12: 983-997, 2017

30. Gupta S, Connolly J, Pepper RJ, Walsh SB, Yaqoob MM, Kleta R and Ashman N: Membranous nephropathy: A retrospective observational study of membranous nephropathy in north east and central London. BMC Nephrol 18: 201, 2017.
31. Yamaguchi M, Ando M, Katsuno T, Tsuboi N and Maruyama S: Urinary protein and renal prognosis in idiopathic membranous nephropathy: A multicenter retrospective cohort study in Japan. Ren Fail 40: 435-441, 2018

32. Heeringa SF, Branten AJ, Deegens JK, Steenbergen E and Wetzels JF: Focal segmental glomerulosclerosis is not a sufficient predictor of renal outcome in patients with membranous nephropathy. Nephrol Dial Transplant 22: 2201-2207, 2007.

33. Ma YC, Zuo L, Chen JH, Luo Q, Yu XQ, Li Y, Xu JS, Huang SM, Wang LN, Huang W, et al: Modified glomerular filtration rate estimating equation for Chinese patients with chronic kidney disease. J Am Soc Nephrol 17: 2937-2944, 2006.

34. Reidy K and Kaskel FJ: Pathophysiology of focal segmental glomerulosclerosis. Pediatr Nephrol 22: 350-354, 2007.

35. Troyanov S, Roasio L, Pandes M, Herzenberg AM and Cattran DC: Renal pathology in idiopathic membranous nephropathy: A new perspective. Kidney Int 69: 1641-1648, 2006.

36. Kuwabara M, Hisatome I, Niwa K, Hara S, Roncal-Jimenez CA, Bjornstad P, Nakagawa T, Andres-Hernando A, Sato Y, Jensen T, et al: Uric acid is a strong risk marker for developing hypertension from prehypertension: A 5-year Japanese cohort study. Hypertension 71: 78-86, 2018.

37. Zhang BO, Cheng M, Yang M, Han S, Zhang YH, Shi HG, Zhu L and Zhao XZ: Analysis of the prognostic risk factors of idiopathic membranous nephropathy using a new surrogate end-point. Biomed Rep 4: 147-152, 2016.

38. Jolly SE, Mete M, Wang H, Zhu J, Ebbesson SO, Voruganti VS, Comuzzie AG, Howard BV and Umans JG: Uric acid, hypertension, and chronic kidney disease among Alaska Eskimos: The genetics of coronary artery disease in alaska natives (GOCADAN) study. J Clin Hypertens (Greenwich) 14: 71-77, 2012.

39. Ihm CG: Hypertension in chronic glomerulonephritis. Electrolyte Blood Press 13: 41-45, 2015.

40. Ponticelli C and Glassock RJ: Glomerular diseases: Membranous nephropathy-a modern view. Clin J Am Soc Nephrol 9: 609-616, 2014.

41. Tomas NM, Beck LH Jr, Meyer-Schwesinger C, Seitz-Polski B, Ma H, Zahner G, Dolla G, Hoxha E, Helmchen U, DabertGay AS, et al: Thrombospondin type-1 domain-containing 7A in idiopathic membranous nephropathy. N Engl J Med 371: 2277-2287, 2014.

42. Beck LH Jr, Fervenza FC, Beck DM, Bonegio RG, Malik FA, Erickson SB, Cosio FG, Cattran DC and Salant DJ: Rituximabinduced depletion of anti-PLA2R autoantibodies predicts response in membranous nephropathy. J Am Soc Nephrol 22: $1543-1550,2011$

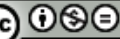

This work is licensed under a Creative Commons Attribution-NonCommercial-NoDerivatives 4.0 International (CC BY-NC-ND 4.0) License. 